\title{
Recommendations for reference method for haemoglobinometry in human blood (ICSH standard 1995) and specifications for international haemiglobincyanide standard (4th edition)
}

\author{
International Council for Standardisation in Haematology: Expert Panel on \\ Haemoglobinometry
}

\begin{abstract}
Introduction
Scientific symposia on haemoglobinometry were held at the 9th Congress of the European Society of Haematology, Lisbon, $1963,{ }^{1}$ and the 10th Congress of the International Society of Haematology (ISH), Stockholm, $1964 . .^{2}$ The International Committee (now Council) for Standardisation in Haematology (ICSH) made recommendations endorsed by the General Assembly of ICSH in Sydney on 23 August 1966, ${ }^{3}$ for a reference method for haemoglobinometry and for the manufacture and distribution of an international reference preparation. Further symposia were held at the 12 th Congress of the ISH, New York, $1968,{ }^{4}$ and at the 13th Congress of the ISH, Munich, $1970 . .^{5}$ The recommendations were reissued in $1978^{6}$ and in $1986 .{ }^{7}$ On the basis of continuing experimental studies, the reference method and the specifications for the international standard have been modified. The revised recommendations are described in this document.
\end{abstract}

\section{Recommendations for reference method} for haemoglobinometry in human blood Haemoglobin is a chromoprotein. On the basis of the chemical structure of two $\alpha$ and two $\beta$ chains and of four haem groups, it is calculated to have a relative molecular mass of 64458 (anhydrous) ${ }^{8-10}$ The mass fraction of haemoglobin iron is therefore 0.00347 .

At the Assemblies in Kyoto, Japan, in 1976 and Budapest, Hungary, in 1984, ICSH recommended that haemoglobin in blood should be expressed as mass concentration in $\mathrm{g} / \mathrm{l}$. In conformity with the joint recommendation for use of the international system of units (SI) in clinical laboratory measurements, as agreed by ICSH, the International Federation of Clinical Chemistry (IFCC), and the World Association of Societies of Pathology (WASP), ${ }^{11}$ substance concentration $(\mathrm{mmol} / \mathrm{l})$ may also be used. In that case the elementary entity (monomer or tetramer) should be specified by use of the notation $\mathrm{Hb}(\mathrm{Fe})$ or $\mathrm{Hb}(4 \mathrm{Fe})$. For measurement of the reference standard the expert panel recommends relating absorptivity and relative molecular mass to one haem group and one quarter of the total globin moiety.

\section{PRINCIPLE}

Photometric determination of haemiglobincyanide ( $\mathrm{HiCN}$ ) (see note 1 ) is recommended as the reference method. If any other method is used in routine measurement (for example, photometric determination of oxyhaemoglobin or haemiglobinazide; iron determination) it should be adjusted to obtain comparability with the haemiglobincyanide method. ${ }^{12}$

\section{REAGENT}

The haemoglobin derivatives occurring in blood, with the exception of sulphaemoglobin (see note 2), are converted into haemiglobincyanide by the use of an appropriate reagent. The reagent must be of such quality that after dilution of the blood there is no turbidity (see note 3); the photometric determination must be delayed until the reaction is completed.

\section{ABSORBANCE MEASUREMENT}

Blood should be diluted suitably (for example, $1: 251 ; 100 \mu$ l of blood $+25 \mathrm{ml}$ reagent $)^{1314}$ with reagent, filtered with a low-binding, low-release membrane filter, 0.2 to $0.25 \mu \mathrm{m}$ mean pore diameter (see note 4 ) to ensure absence of all particulate matter, and measured at $540 \mathrm{~nm}$ (see note 5) against an appropriate blank (see note 6).

The photometer must be calibrated as to wavelength and should be checked frequently as to linearity (see note 7) and the absence of stray light; the absorbance scale should be checked before each measurement series withfor example, a certified glass filter, or a solution \\ 18 October 1995
}


of known absorbance-for example, a secondary haemoglobin standard. Even minor changes in the set-up may cause significant deviations in calibration.

\section{CALIBRATION STANDARD}

The haemiglobincyanide calibration standard should be an aqueous solution of haemiglobincyanide with a concentration in the range $550-850 \mathrm{mg} / 1$ (see note 8 ). It is strongly recommended that it be dispensed as a sterile solution in individual doses in sealed glass ampoules. The spectrophotometric characteristics must conform to the specifications of the International Haemiglobincyanide Standard: $1.59 \leq \mathrm{A}_{\mathrm{HiCN}}^{540} / \mathrm{A}_{\mathrm{HiCN}}^{504} \leq 1.63 ; \mathrm{A}_{\mathrm{HiCN}}^{750} \leq 0.003$ per cm lightpath length; and an absorbance spectrum characteristic for pure $\mathrm{HiCN}$ solutions. ${ }^{15}$

\section{DETERMINATION OF HAEMOGLOBIN} CONCENTRATION

Because HiCN solutions strictly follow Lambert-Beer's law, the haemoglobin concentration is calculated using the relation between absorbance and $\mathrm{HiCN}$ concentration established in the calibration procedure. If this relation is found to be in conformity with $\varepsilon=$ $11 \cdot 01 . \mathrm{mmol}^{-1} . \mathrm{cm}^{-1}$, the haemoglobin concentration is calculated by means of the following equation:

$$
\mathrm{c}(\mathrm{g} / \mathrm{l})=\frac{\mathrm{A}_{\mathrm{HiCN}}^{540} \times \mathrm{M} \times \mathrm{F}}{\varepsilon_{\mathrm{HiCN}}^{540} \times 1 \times 1000}
$$

where $A_{\mathrm{HiCN}}^{540}=$ absorbance of the solution at $\lambda=$ $540 \mathrm{~nm} ; M=$ relative molecular mass of haemoglobin, derived from $64458 / 4^{9} ; \mathrm{F}=$ dilution factor used (for example, 251); $\varepsilon_{\mathrm{HiCN}}^{540}=$ millimolar absorptivity $=11 \cdot 0^{1718} ; 1=$ lightpath in $\mathrm{cm}$; and $1000=$ conversion factor $\mathrm{mg}$ to $\mathrm{g}$. For a dilution (F) of 251 and a lightpath of $1.000 \mathrm{~cm}$ :

$$
\mathrm{c}(\mathrm{g} / \mathrm{l})=367 \cdot 7 \times \mathrm{A}_{\mathrm{HiCN}}^{540}
$$

\section{International haemiglobincyanide standard MANUFACTURE}

The international haemiglobincyanide standard (see note 9) is manufactured at three to five year intervals; details of the method are given by Holtz. ${ }^{19}$ It is made from washed red cells from human blood tested for the absence of hepatitis and HIV antibodies, haemolysed by toluene, and centrifuged-free from debris. The haemoglobin is converted to haemiglobincyanide. The final solution has a haemiglobincyanide concentration of $550-850 \mathrm{mg} / 1$. It is dispensed in sealed $10 \mathrm{ml}$ glass ampoules as a sterile solution after membrane filtration (see note 10).

\section{EVALUATION AND CONTROL}

Each batch is tested in laboratories nominated by the ICSH Board (see note 11), in accordance with the principles set out below. The results are analysed by a consultant who advises the ICSH Secretariat on the control of the preparation.

\section{CONCENTRATION}

The HiCN concentration is calculated from the results of at least five laboratories, using the equation:

$$
c(g / 1)=\frac{A_{\mathrm{HiCN}}^{540} \times 16114.5}{11.0 \times 1.000}=1465 \times \mathrm{A}_{\mathrm{HiCN}}^{540}
$$

where $A_{\mathrm{HiCN}}^{540}=$ absorbance of the solution at $\lambda=$ $540 \mathrm{~nm} ; 16114.5=$ relative molecular mass of haemoglobin monomer, derived from 64 458/ $4^{9} ; 11 \cdot 0=\varepsilon_{\mathrm{HiCN}}^{540}$ (millimolar absorptivity) (see note 12$) ; 1.000=$ lightpath in $\mathrm{cm}$.

An equivalent haemoglobin concentration of the standard may be calculated by multiplying the HiCN concentration by the dilution factor (F) used in the method-for example, 251 for $100 \mu \mathrm{l}$ blood plus $25 \mathrm{ml}$ reagent.

Using an appropriate blank (see note 6), $\mathrm{A}_{\mathrm{HiCN}}^{540}$ is measured on a spectrophotometer, the wavelength scale of which has been calibrated with the aid of the mercury (or hydrogen or deuterium) emission spectrum, or holmium oxide in perchloric acid ${ }^{2021}$; on which absorption checks have been performed using calibrated glass filters or other means which have been certified by a standardising authority (see note 13); and of which the absence of stray light has been verified. Its slit width is chosen so that the half intensity bandwidth is less than or equal to $2 \mathrm{~nm}$. The cuvettes in which the solution is measured are plan-parallel with an inner wall to wall distance of $1.000 \mathrm{~cm}$, tolerance $0.5 \%(0.995-1 \cdot 005)$. The measurements are carried out at $20-25^{\circ} \mathrm{C}$.

The arithmetical mean and standard error of the results of the laboratories are recorded after erratic results, if any, have been discarded in accordance with statistical practice. ${ }^{22} \mathrm{Ex}$ perience with this procedure has shown that the confidence limits of the final results are within $\pm 1 \%$.

\section{PURITY}

The purity is controlled by (1) judging the shape of the absorbance curve between $\lambda=450$ and $750 \mathrm{~nm}$, lightpath length $1.000 \mathrm{~cm}$ (see note 14$)$; (2) determining the quotient $\mathrm{A}_{\mathrm{HiCN}}^{540} / \mathrm{A}_{\mathrm{HiCN}}^{504}$, the value of this quotient should lie between 1.59 and 1.63 ; and (3) measuring at a wavelength between 730 and $770 \mathrm{~nm}$ (nearinfrared) to check turbidity. This absorbance should be $\leq 0.003$ per $\mathrm{cm}$ lightpath length, using an appropriate blank (see note 6 ).

\section{STABILITY}

The stability is checked by ICSH testing laboratories several times each year. The manufacturing laboratory repeats absorbance measurements at more frequent, regular intervals. The International Reference Standard is kept at $4^{\circ} \mathrm{C}$. It is stable for more than six years. ${ }^{1523}$ 
STERILITY

In conformity with current practice of sterility control, the contents of the ampoules to be tested are innoculated in aerobic and anaerobic media and incubated at 22 and $37^{\circ} \mathrm{C}$ (see note 15).

\section{LABELLING}

The International Standard is labelled with the batch number, the value of its haemiglobincyanide concentration (mean and standard error; see concentration), and an expiry date which is considered well within safe limits (see stability).

The producer notifies all customers if continuing control of stability indicates that a particular batch is no longer acceptable.

\section{PURPOSE AND DISTRIBUTION}

The ICSH International Standard is used to assign values to secondary $\mathrm{HiCN}$ reference solutions or $\mathrm{HiCN}$ calibration solutions, and as a reference against which to judge the purity of such HiCN solutions.

The International Standard is made available for reference use only to national standards committees for haematological methods or to official government nominated holders (see note 16). Where there is no committee or official holder, it may be distributed to individuals approved by ICSH.

The national holder must ensure that an opportunity is given to manufacturers and distributors to use the International Haemiglobincyanide Standard as a reference material if so desired, in conformity with national requirements.

Information about national committees, official holders, and other contact persons may be obtained from the ICSH Secretariat, c/o Dr R M Rowan, Haematology Department, Western Infirmary, Dumbarton Road, Glasgow G11 6NT

\section{Notes}

(1) Alternative terms for haemiglobincyanide are cyanmethaemoglobin and cyanferrihaemoglobin.

(2) Sulphaemoglobin is converted to sulphaemiglobincyanide. It has, however been calculated that the presence of $1 \%$ sulphaemoglobin in a blood specimen causes the total haemoglobin concentration to be underestimated by no more than $0.27 \%{ }^{24}$; in clinical practice sulphaemoglobin fractions exceeding 0.05 are seldom encountered.

(3) A suitable reagent, recommended by van Kampen and $\mathrm{Zijlstra}{ }^{25}$ is prepared as follows: dissolve $200 \mathrm{mg} \mathrm{K}_{3} \mathrm{Fe}(\mathrm{CN})_{6}, 50 \mathrm{mg} \mathrm{KCN}$, $140 \mathrm{mg} \mathrm{KN} \mathrm{PO}_{4}$ (analytical grade chemicals), and an appropriate amount of non-ionic detergent in water and dilute to 1 litre. The $\mathrm{pH}$ must be $7 \cdot 0-7 \cdot 4$; the osmolality $6-7 \mathrm{mmol} /$ $\mathrm{kg}$. The absorbance at $\lambda=540 \mathrm{~nm}$, measured against water as blank, should be zero. If stored at room temperature in a brown borosilicate glass bottle, the solution keeps for at least two months at approximately $20^{\circ} \mathrm{C} . \mathrm{K}_{3} \mathrm{Fe}(\mathrm{CN})_{6}$ is destroyed by freezing; this decomposition can be prevented by the addition of ethanol, methanol, ethylene glycol $(20 \mathrm{ml} / \mathrm{l})$, or glycerol $(5 \mathrm{ml} / 1) .{ }^{26}$ Examples of suitable non-ionic detergents are Nonidet P40 (Shell International) $1 \mathrm{ml} / 1$ and Triton X-100 (Rohm and Haas) $1 \mathrm{ml} / 1$. They are available in general from laboratory chemical suppliers. The reagent has a conversion time of three to five minutes in contrast to the original or modified Drabkin's reagent with a conversion time of 15 minutes or more. Because of the longer conversion time, as well as the greater incidence of turbidity, these other reagents are not recommended. A modified van Kampen-Zijlstra reagent has been described $^{27}$ for suppression of turbidity in samples from patients with a high white blood cell count or a high $\gamma$ globulin concentration. The conversion time of carboxyhaemoglobin to $\mathrm{HiCN}$ is considerably longer, up to $30 \mathrm{~min}$ utes. ${ }^{15}$

(4) Examples of low-binding, low-release filters are $(0.22 \mu \mathrm{m})$ polyvinylidene difluoride MillexGV (Millipore) and $(0.20 \mu \mathrm{m})$ polypropylene Paradisc 25 PP (Whatman). (B. Houwen, Loma Linda University Medical School: personal communication).

(5) High resolution spectrophotometry by the panel and by the US National Institute of Standards and Technology has shown the wavelength of maximal absorbance to be $541 \cdot 05 \pm 0 \cdot 11 \mathrm{~nm}$, and an absorbance minimum to be at $503.47 \pm 0.14 \mathrm{~nm}$. When measuring at $540 \mathrm{~nm}$, the absorbance difference with respect to $541.05 \mathrm{~nm}$ is $0.1 \%$.

(6) The reagent does not absorb light (see note 3). Some modern spectrophotometers have, however, been identified that show apparent light absorption between 500 and $600 \mathrm{~nm}$ by the reagent. It is not clear whether this apparent absorption is caused by stray light or by internal cuvette reflections. The laboratory should thus verify that, for a particular instrument-cuvette combination, the reagent does not absorb light. If apparent light absorption is found, a reagent blank should be used when measuring.

(7) Linearity may be verified using a procedure such as that described by Eilers and Crocker $^{28}$ with a sterile, membrane-filtered (at pore size $0 \cdot 2-0 \cdot 25 \mu \mathrm{m}$ ) haemiglobincyanide calibration standard. With present-day spectrophotometers, calibration may resolve itself into verifying that the instrument yields an accurate value for $\mathrm{A}_{\mathrm{HiCN}}^{540}$ of a secondary haemiglobincyanide standard. Slight deviations from the expected $\mathrm{A}_{\mathrm{HiCN}}^{540}$ value may be used to correct measurement results.

(8) Solutions of lower concentration are not reliable.

(9) The standards were originally designated by the World Health Organisation (WHO) ${ }^{29}$ as International Haemiglobincyanide Reference Preparations. They are now designated International Haemiglobincyanide Standards.

(10) It was agreed that, whereas the International Reference Preparation would be aqueous, national boards might provide glycerinated solutions if preferred. 
(11) At present these laboratories are Atlanta (USA), Scientific Resources Program, NCID, Centers for Disease Control and Prevention (O W van Assendelft); Emmen (The Netherlands), Scheperziekenhuis (A Zwart); Gaithersburg (USA), Laboratory of the College of American Pathologists, National Institute of Standards and Technology (M Welch); Groningen (The Netherlands), University of Groningen, Faculty of Medicine (W G Zijlstra); Loma Linda (USA), Loma Linda University Medical School (B Houwen); London (UK), Royal Postgraduate Medical School (S M Lewis); Rome (Italy), Instituto Superiore di Sanita (A M Salvati).

(12) See van Kampen and Zijlstra ${ }^{15}$, Zijlstra and van Kampen ${ }^{17}$, and van Assendelft and Zijlstra. ${ }^{18}$

(13) See Menzies ${ }^{30}$ and National Bureau of Standards. ${ }^{31}$

(14) See van Kampen et $a l^{13}$ and van Kampen and Zijlstra. ${ }^{15}$

(15) Always checked by the producer.

(16) The distribution is sponsored by the WHO. $^{29}$

1 ESH. Haemoglobinometry: erythrocytometric methods and their standardization. Bibl Haematol 1964;18:59-85.

$2 \mathrm{ISH}$. Haemoglobinometry and molecular weight of haemoglobin. Standardization, documentation and normal values in haematology. Bibl Haematol 1965;21:25-102.

3 ICSH. Recommendations for haemoglobinometry in human blood. Br ₹ Haematol 1967;13(Suppl):71-6.

4 Astaldi G, Sirtori C, Vanzetti G (eds). Standardization in haematology. Milan: Fondazione Carlo Erba, 1969.

5 Izak G, Lewis SM (eds). Modern concepts in haematology. New York: Academic Press, 1972.

6 ICSH. Recommendations for reference method for haemoglobinometry in human blood (ICSH Standard EP6/2 1977) and specification for international haemiglobincyanide reference preparation (ICSH Standard EP6/3:1977). F Clin Pathol 1978;31:139-43.

7 ICSH. Recommendations for reference method for haemoglobinometry in human blood (ICSH standard 1986) and specifications for international haemiglobincyanide reference preparation (3rd edition). Clin Lab Haematol reference prepa

8 Braunitzer G, Gehring-Muller R, Hilschmann N, Hilse K, Hobom G, Rudloff V, et al. Die Konstitution des normalen adulten Humanhämoglobins. Hoppe-Seylers Zeitschrift für physiologische Chemie 1961;325:283-6.

9 Braunitzer G. The molecular weight of haemoglobin. Bibl Haematol 1964;18:59-60.

10 Hill RJ, Konigsberg W, Guidotti G, Craig LC. The structure of human hemoglobin. Parts 1-5. F Biol Chem 1962;237: 1549-54;2184-95;2547-61;3151-6;3157-62.

11 ICSH, IFCC, WASP. Recommendations for use of SI in clinical laboratory measurements. Br 7 Haematol 1972;23: 787; Z Klin Chem Klin Biochem 1973;11:93.
12 Kwant G, Oeseburg B, Zwart A, Zijlstra WG. Calibration of a practical haemoglobinometer. Clin Lab Haematol 1987;9. 387-93.

13 van Kampen EJ, Zijlstra WG, van Assendelft OW, Reinkingh WH. Determination of hemoglobin and its derivatives. Adv Clin Chem 1965;8:141-87.

14 van Assendelft OW. Spectrophotometry of haemoglobin derivatives. Assen: van Gorcum, 1970; Springfield, Illinois: Charles C Thomas, 1970

15 van Kampen EJ, Zijlstra WG. Spectrophotometry of hemoglobin and hemoglobin derivatives. Adv Clin Chem 1983;23:199-257.

16 Zijlstra WG, Buursma A, Zwart A. Molar absorptivities of human hemoglobin in the visible spectral range. $\mathcal{F} A p p$ Physiol 1983;54:1287-91.

17 Zijlstra WG, van Kampen EJ. Standardization of hemoglobinometry. I. The extinction coefficient of hemiglobincyanide at $\lambda=540 \mathrm{~m} \mu: \varepsilon_{\text {HiCN }}^{540}$ Clin Chim Acta 1960 ; 5:719-26.

18 van Assendelft OW, Zijlstra WG. Extinction coefficients for use in equations for the spectrophotometric analysis of haemoglobin mixtures. Anal Biochem 1975;69:43-8.

$19 \mathrm{Holtz}$ AH. Some experience with a cyanhemiglobin solution. Bibl Haematol 1965;21:75-8.

20 Jansen AP, van Kampen EJ, Steigstra H, van der Ploeg PHW, Zwart A. Simultaneous spectrophotometric calibration of wavelength and absorbance in an interlaboratory survey using holmium oxide $\left(\mathrm{Ho}_{2} \mathrm{O}_{3}\right)$ in perchloric acid as reference, compared with p-nitrophenol and cobaltous sulfate solutions (1978-1984). F Clin Chem Clin Biochem 1986; 24:141-6.

21 Weidner VR, Mavrodineanu R, Mielenz KD, Velapoldi RA Eckerle KL, Adams B. Spectral transmittance characteristics of holmium oxide in perchloric acid solution fournal of Research of the National Bureau of Standards fournal of Research

22 Dixon WJ. Processing data for outliers. Biometrics 1953;9: 74-89.

23 van Assendelft OW, Buursma A, Holtz AH, van Kampen EJ, Zijlstra WG. Quality control in haemoglobinometry with special reference to the stability of haemiglobincyanide reference solutions. Clin Chim Acta 1976; 70:161-9.

24 Dijkhuizen P, Buursma A, Gerding AM, Ziilstra WG Sulfhaemoglobin. Absorption spectrum, millimolar extinction coefficient at $\lambda=620 \mathrm{~nm}$, and interference with the determination of haemoglobin and of haemithe determination of haemoglobin and of

25 van Kampen EJ, Zijlstra WG. Standardization of hemoglobinometry. II. The hemiglobincyanide method. Clin Chim Acta 1961;6:538-44.

26 Zweens J, Frankena H, Zijlstra WG. Decomposition on freezing of reagents used in the ICSH-recommended method for the determination of total haemoglobin in blood, its nature, cause, and prevention. Clin Chim Acto 1979;91:337-52.

27 Matsubara T, Okuzono H, Senba U. A modification of van Kampen-Zijlstra's reagent for the hemiglobincyanide van Kampen-Zijlstra's reagent for the hemi
method. Clin Chim Acta 1979;93:163-4.

28 Eilers R, Crocker C. The value of Ringbom curves in hemoglobinometry. In: Izak G, Lewis SM, eds. Modern concepts in hematology. New York: Academic Press, 1972 58-65.

29 World Health Organization. WHO Expert Committee on Biological Standardization. 20th Report. World Health Organ Tech Rep Ser 1968;384:12-13;86-7.

30 Menzies AC. Report on calibration of wavelength and photometric scales of non-recording spectrophotometers. Pure Appl Chem 1960;1:147-62.

31 National Bureau of Standards. Standard reference materials No. 51: Glass filters as a standard reference material for spectrophotometry. NBS Special Publication 260. Washington DC: Government Printing Office, 1975. 